\title{
ON THE INFLUENCE OF THE ANNEALING HEATING RATE ON THE RECRYSTALLIZATION TEXTURE OF A DEFORMED SINGLE CRYSTAL (110)[001] OF 3\% SILICON IRON
}

\author{
B. K. SOKOLOV, A. K. SBITNEV, V. V. GUBERNATOROV, \\ I. V. GERVASYEVA and L. R. VLADIMIROV \\ Metal Physics Institute, Russian Academy of Sciences, S. Kovalevskaya str., \\ 18, 620219, Ekaterinburg, Russia
}

(Received 8 November 1995)

\begin{abstract}
The reasons for changes in the type of the recrystallizatioin texture depending on particular annealing conditions of a deformed single crystal (110)[001] are discussed. It is shown that recrystallization centers (210)-(310)[001] can be formed at structural inhomogeneities of different type, such as transition bands, kink bands, and twin boundaries. The development of the texture component (210)-(310)[001] in deformed single crystals subject to slow heating is due mainly to the orientation dependence of the critical dimension of nuclei.
\end{abstract}

KEY WORDS: Rolling texture, Structural inhomogeneities, Oriented nucleation, Recrystallization texture.

\section{INTRODUCTION}

Most studies performed by $\mathrm{H}$. $\mathrm{Hu}$ were dedicated to microscopic examination of deformation and recrystallization processes in metals and alloys with the view of elucidating the mechanisms of texture formation. In this respect, of great value to the theory and practice of material treatment were studies into microheterogeneity of the deformed state and its effect on the recrystallization texture formation.

The range of materials studied by $\mathrm{H}$. Hu was quite diverse. Out of $\mathrm{BCC}$ materials, the $\mathrm{Fe}-3 \% \mathrm{Si}$ alloy was his favorite. It is on this alloy that he showed the role played by coalescence of grains in the formation of a recrystallized structure and ascertained some mechanisms of texture transformation ( $\mathrm{Hu}, 1966)$.

$\mathrm{Hu}$ (1960) was the first who noted the temperature and heating rate dependence of the recrystallization texture in a single crystal (110)[001] of 3\% silicon iron, which was deformed by rolling with a $70 \%$ reduction. The single crystal had the texture (110)[001] under rapid heating and the texture (210)[001] under slow heating. Subsequently this result was confirmed time and again. But even now the phenomenon is difficult to explain.

Commemorating $\mathrm{H}$. $\mathrm{Hu}$, this paper represents a follow-up of his investigations of microstructures and textures aimed at elucidating the influence of particular annealing conditions on the formation of textures in a deformed single crystal (110)[001] of $3 \%$ silicon iron. 


\section{PROBLEM STATEMENT}

Plastic deformation of single crystals (110)[001] leads to their strong structural inhomogeneity. The basic structural elements found in deformed single crystals are shown in Figure 1.

The deformation bands (1) represent large re-oriented regions extended along the rolling direction (RD). They appear as a result of neighbouring portions of the single crystal turning in opposite directions about transverse direction (TD) (Hu, 1960; Taoka, Furubayashi, Takeuchi, 1967). In a single crystal (110)[011] reduced to 70\% neighboring bands have the orientations (111)[112] and (111)[1 12$]$. The boundaries between the deformation bands are transition bands (2), which represent narrow (1-3 $\mu \mathrm{m})$ regions with a gradual change of the orientation from one deformation band to another. Transition bands also contain volumes with the initial orientation of the single crystal. Inhomogeneities of a different type are concentrated within each of the deformation bands. Their traces in the rolling plane are perpendicular to RD (3). The inhomogeneities are often referred to as transition bands, although they appear in structural regions with a single orientation. In our opinion the said inhomogeneities would be more properly classified as kink bands (Honeycombe, 1968). Formation of the kink bands is due to retardation of the dislocations slip by obstacles, this increasing the concentration of one-sign dislocations and leading to a local bend of the crystal lattice. Despite the fact that these bands are formed in a single-orientation matrix, they may possess a broad

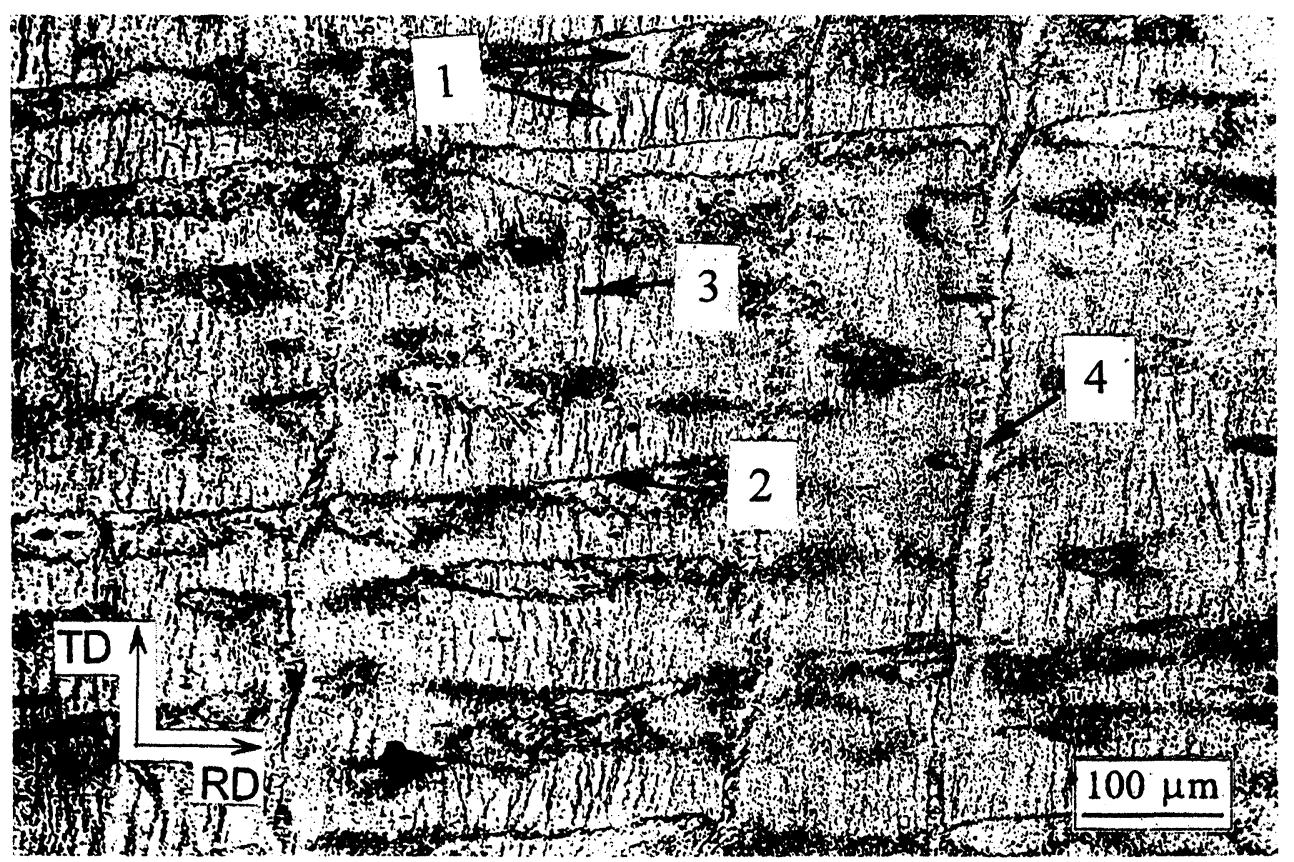

Figure 1 Types of structure inhomogeneities in rolled single crystal (110)[001]: 1-deformation bands; 2-transition bands; 3-kink bands; 4-twins. 
spectrum of orientations (Furubayashi, 1969). The structure also contains deformation twins (4), which are formed during rolling of a single crystal (110)[001] even at room temperature.

The structural inhomogeneity of deformed single crystals affects nucleation and development of recrystallization centers and the texture being formed (Gorelik and Goldstein, 1968). Early appearance of recrystallization nuclei at structural inhomogeneities is explained by maximum distortions of the crystal lattice and large stresses arising in the said regions, which facilitate growth of subgrains and their transformation into recrystallization nuclei with mobile boundaries.

Annealing of deformed single crystals (110)[001] is accompanied by appearance of recrystallization centers with different orientations. However, the grains (110)[001] grow most rapidly and it is these grains that form the basic component of the recrystallization texture (Hu, 1961). The orientation relationships between (110)[001] and the basic components of the deformation texture $\{111\}<112>$ satisfy the conditions of formation of high-mobility boundaries in BCC metals (rotation through $35^{\circ}$ about axes of the $<110>$ type).

Only some suppositions are available with respect to the reasons for formation of the texture (210)[001] in the same deformed single crystals subject to slow heating.

Livshitz et al. $(1969,1970,1972)$ holds to the opinion that nuclei with the orientation (210)[001] are formed at twin boundaries and those with the orientations (110)[001] appear in transition bands. The centers (210)[001] appear before the centers (110)[001] are formed, but the growth rate of the former is lower owing to less favorable orientation relationships with the basic components of the deformation texture. The said authors did not consider nucleation of grains in kink bands. $\mathrm{H}$. Hu disregarded twins in the texture formation, although he demonstrated deformation textures, which had a twin orientation close to (100)[011].

A different opinion was voiced in Gubernatorov's Ph.D. thesis (1975). When a single crystal rolled to obtain certain degrees of deformation is annealed, recrystallization centers are formed first in transition bands. The orientation of the recrystallization centers is close to (210)[001], this reflecting the tendency to a crosswise scattering of the texture as a result of widening of the single crystal. The recrystallization centers, which appear subsequently in kink bands, have the preferred orientation (110)[001].

The goal of our study was to test the validity of the above suppositions.

\section{MATERIALS AND METHODS}

Samples $20 \times 15 \times 0.5 \mathrm{~mm}$ in size were cut from one flat single crystal of $\mathrm{Fe}-3 \%$ Si deviating for $6^{\circ}$ from (110). The exact orientation of the plane is given by the indices (541).

The samples were deformed by rolling in a laboratory quarto mill with working rolls $55 \mathrm{~mm}$ in diameter.

Different number of twins in the deformed single crystals was provided thanks to different temperatures of the first pass with a 3-\% reduction. Rolling at room temperature resulted in formation of a very small number of twins ( 1 twin or 2 twins intersect a length of $1 \mathrm{~cm}$ on the surface of a single crystal along the rolling direction). Deformation performed at the temperature of liquid nitrogen increased the number of twins to $35-45 \mathrm{~cm}^{-1}$. First reduction at a temperature of $100-200^{\circ} \mathrm{C}$ excluded appearance of deformation twins altogether. 
The number of transition bands and that of kink bands were characterized by the number of their intersections with a 1-mm length extending perpendicular and parallel to the rolling direction respectively.

The deformed samples were annealed under the following conditions:

- heating in a salt bath at $800^{\circ} \mathrm{C}$ and holding for $40 \mathrm{sec}$. (regime 1);

- charging in a hot furnace at $800^{\circ} \mathrm{C}$ and holding for 3 min. (regime 2);

- heating at a rate of $10-15^{\circ} \mathrm{C} /$ hour over the temperature interval of 300 to $700^{\circ} \mathrm{C}$ (regime 3).

Annealing with a gradient distribution of the temperature along the length of the samples from 300 to $700^{\circ} \mathrm{C}$ was carried out.

The deformation and recrystallization textures were examined by the pole figures method using X-ray diffracometer and the Schultz technique in $\operatorname{CoK} \alpha$ radiation.

During microstructure investigations the dislocation structure was determined using electrolytic etching in the Shostak reagent after additional decoration of dislocations at a temperature of $300^{\circ} \mathrm{C}$. Orientation of individual grains was determined from etchpit patterns with an accuracy of $2^{\circ}$.

\section{TEXTURE AND STRUCTURE OF DEFORMED AND RECRYSTALLIZED CRYSTALS}

As was mentioned in the foregoing, lengthwise rolling of single crystals (110) in the direction [001] with a reduction of 70-80\% results in a texture comprising strong doublet components of the $\{111\}<112>$ type.

By changing the deformation conditions, it is possible to obtain different intensity ratios of doublet components. Such deformation methods as rolling-drawing (Ageev et al., 1973), angle rolling (Bryshko, Gubernatorov, Sokolov, (1985), and unidirectional lengthwise many-passes rolling (Gubernatorov, 1975) lead to the formation of a onecomponent deformation texture (111) [ $\overline{1} \overline{1} 2]$ with a certain fraction of weak components including the initial orientation of the single crystal.

In our study, to obtain different ratios of doublet components of the $\{111\}<112>$ type, the single crystals were rolled to a total reduction of 50,70 or $80 \%$ in the direction [001] in 1-2 passes with lubrication (treatment A), in 30-50 passes with lubrication (B), or with a high friction coefficient (rolling in paper sheath (Furubayashi, Kikuchi, 1977), treatment C). The intensity ratio of the doublet components in the test samples varied between 1.6 and 25 (Table 1).

An examination of the deformation texture showed that at a $50 \%$ reduction formation of a stable texture of the $\{111\}<112>$ type is not yet complete. Figure 2 displays pole figures of the deformation textures in single crystals subject to a $70-\%$ or $80 \%$ reduction. The intensity ratio of doublet components in the samples, which underwent treatments $\mathrm{A}, \mathrm{B}$ and $\mathrm{C}$, is equal to $1.5,3.5$ and 19 respectively.

Reduction to $70 \%$ and $80 \%$ leads to appearance of strong components of the $\{111\}<112>$ type, whose orientation differs somewhat from the ideal one. This fact is probably due to a deviation of the initial orientation of the single crystal from (110)[001]. As the degree of deformation is increased, the texture deviates towards the planes (132) and $(13 \overline{2})$. This can also be attributed to the initial orientation of the single crystal. 
Table 1 Effect of rolling treatment of crystals on the ratio of pole densities $\left(\mathrm{P}_{1} / \mathrm{P}_{2}\right)$ of symmetrical doublet components $\{111\}<112>$ in deformation textures.

\begin{tabular}{lcc}
\hline Rolling treatment & Full reduction, $\%$ & $\left(P_{1} / P_{2}\right)$ \\
\hline A. 1-2 passes rolling with lubrication & 70 & $1.5-2.0$ \\
& 80 & $1.4-2.0$ \\
B. $30-50$ passes rolling with lubrication & 70 & $2.6-8.0$ \\
& 80 & $2.1-7.2$ \\
C. $30-50$ passes rolling with a high friction in the bite & 70 & $8.5-20.0$ \\
\hline
\end{tabular}

(a)

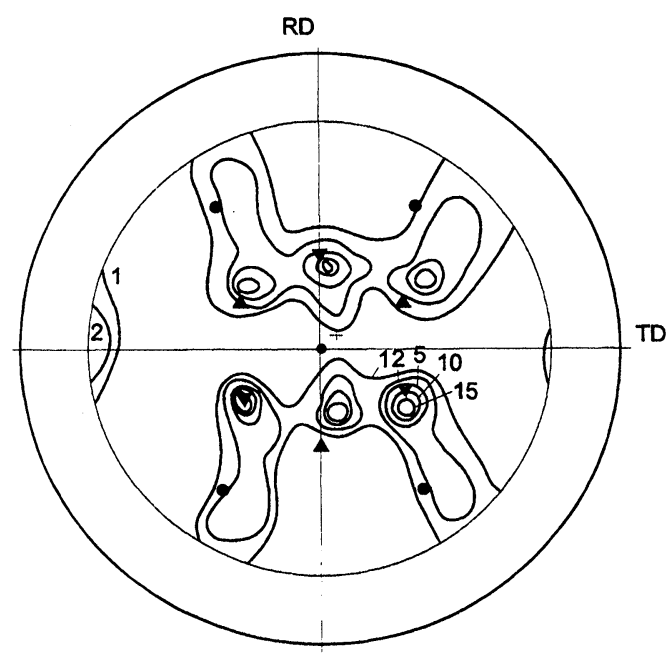

(b)

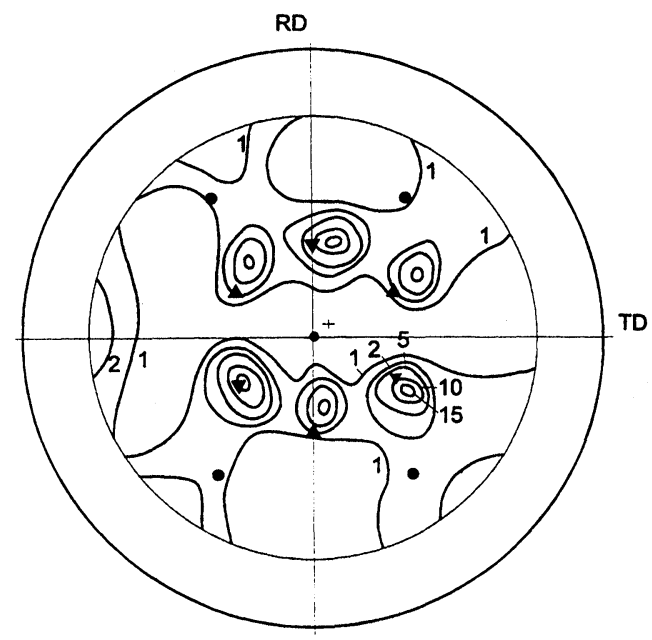


(c)
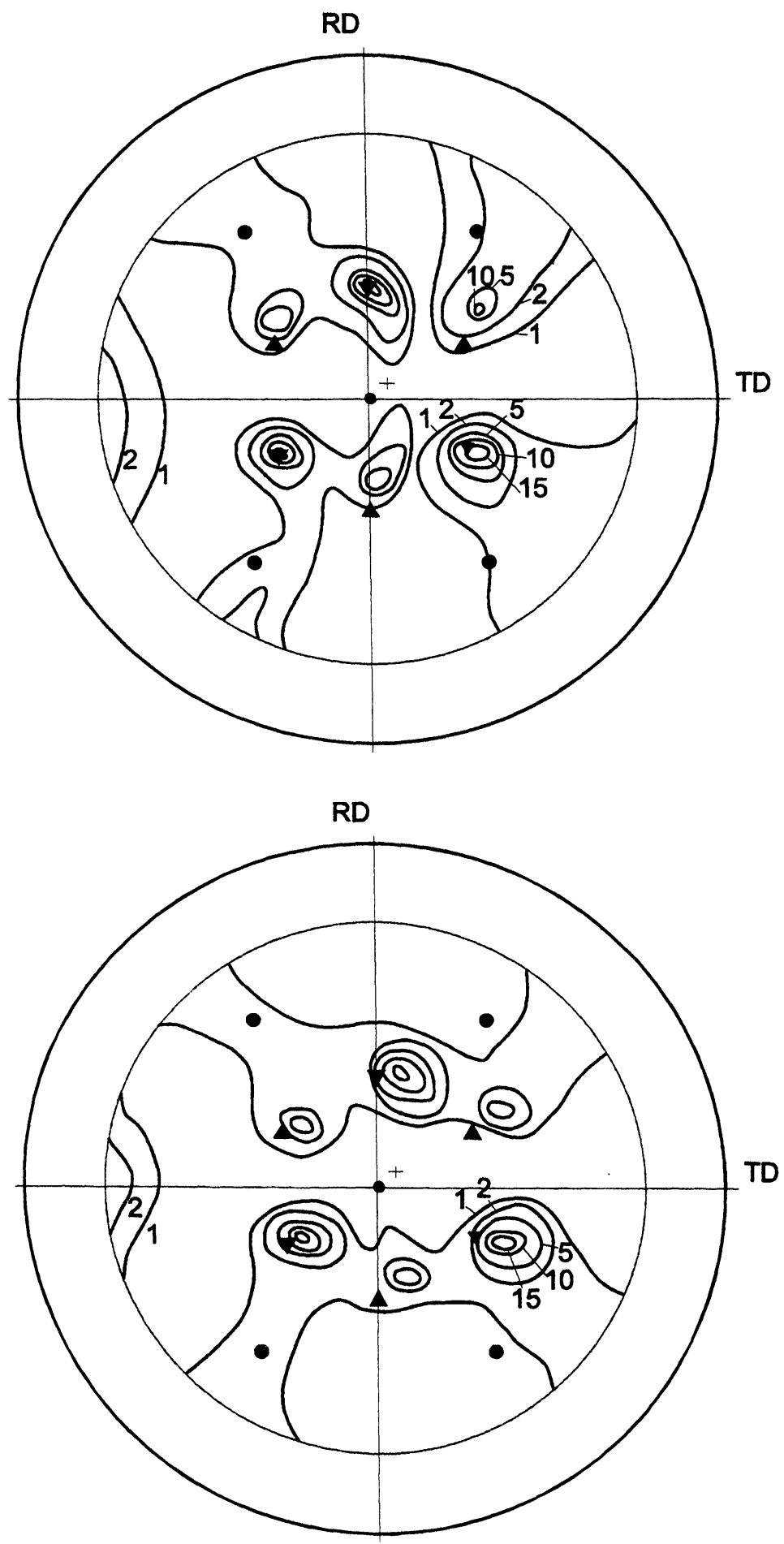
(e)
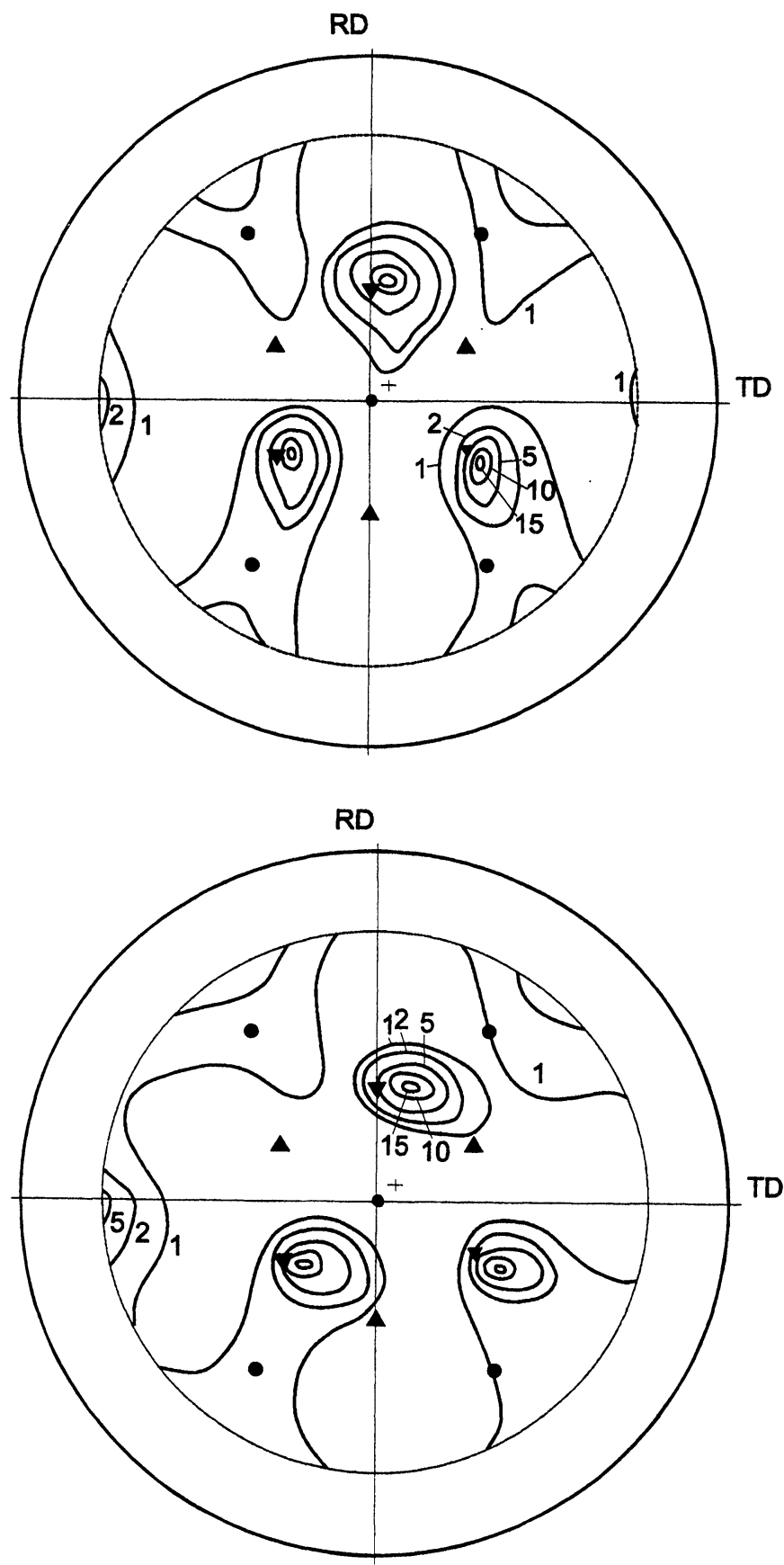

(f)

Figure $2 \quad\{110\}$ pole figures of $(110)[001]$ crystals, rolled by different regimes to $70 \%(a, c, e)$
and $80 \%(b, d, f)$ reduction: a,b - A treatment; c,d - B treatment; e,f - C treatment.

- (110)[001], $\boldsymbol{\nabla}, \Delta-\{111\}<112>, \mathbf{\Delta}-$ the initial orientation of the single crystal. 
After rolling in many passes (treatments B and C) the texture evolution exhibits a preferred rotation of the initial orientation to one side. With an increase in the friction coefficient, an almost one-component deformation texture is produced.

Particular deformation conditions also have a strong effect on the microstructure of a deformed single crystal. When subject to the treatment $A$, the single crystal exhibited well-defined deformation bands extended along RD and wave-like traces of kink bands extended along TD (Figure 3a). The samples, which underwent rolling in many passes

(a)

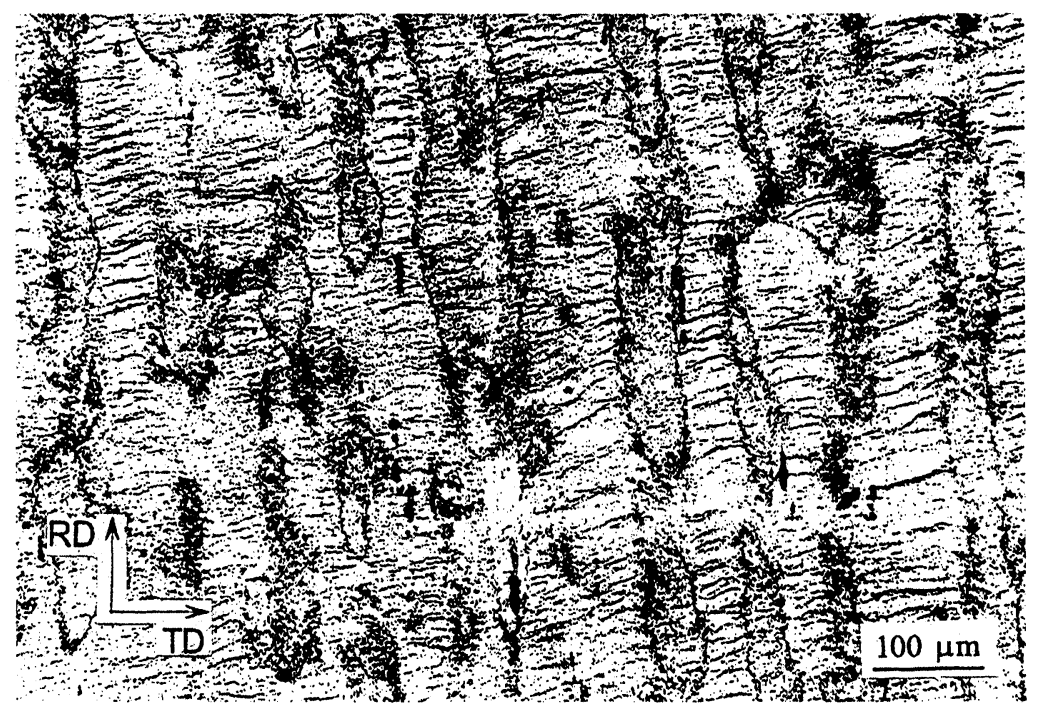

(b)

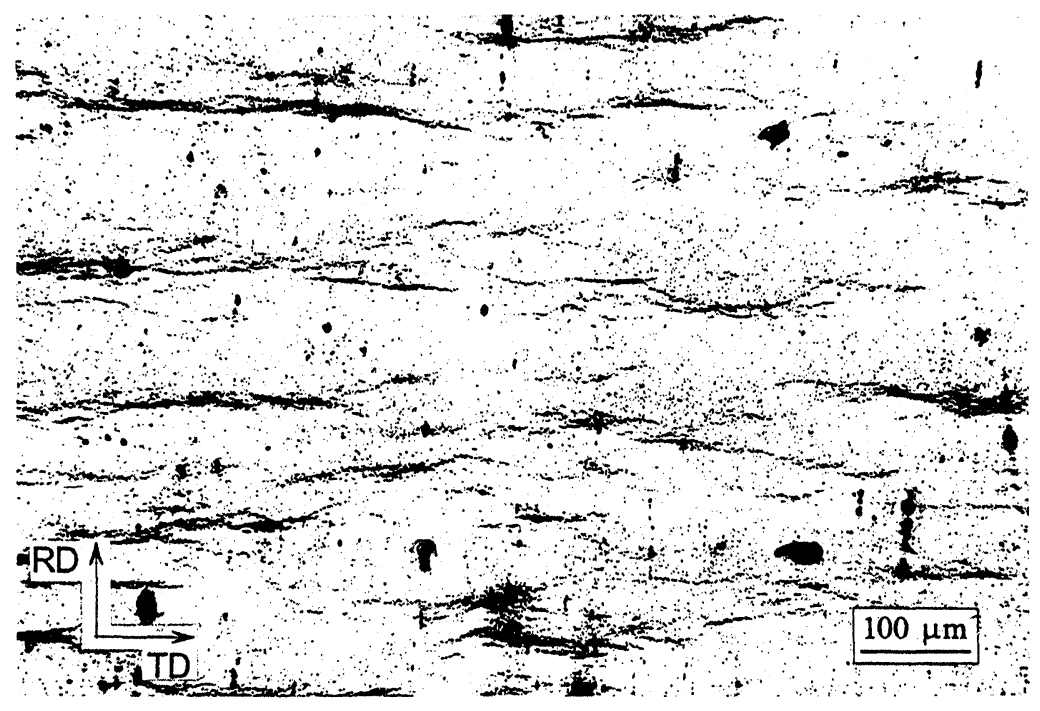

Figure 3 Microstructures of (110)[001] crystals, rolled by different regimes to $70 \%$ reduction: a A treatment; $b-c$ treatment. 
with a high friction coefficient (treament $\mathrm{C}$ ), had only traces of kink bands, the distance between which was larger than the one observed in the case of treatment A (Figure $3 b)$. Table 2 gives some structural parameters of the single crystals deformed to $70 \%$ under treatments $\mathrm{A}$ and $\mathrm{B}$. The same table contains data for single crystals with a large number of twins. The presence of twins changes little if at all with the number of the kink bands formed, but lowers the number of transition bands. Besides, samples with twins have a higher intensity ratio of doublet components.

Table 3 presents the distribution of the pole density along TD from the center of the pole figure $\{110\}$ in crystals deformed under different regimes. The tabulated data

Table 2 Quantity of structure inhomogeneities in crystals, rolled to $70 \%$

\begin{tabular}{|c|c|c|c|}
\hline Rolling treatment & Transition bands, $\mathrm{mm}^{-1}$ & Kink bands, $\mathrm{mm}^{-1}$ & Twins, $\mathrm{mm}^{-1}$ \\
\hline $\begin{array}{l}1-2 \text { passes rolling: } \\
70 \% \text { without twins }\end{array}$ & 21 & 74 & 0,12 \\
\hline $70 \%$ with twins & 12 & 75 & 4,1 \\
\hline $\begin{array}{l}30-50 \text { passes rolling: } \\
70 \% \text { without twins }\end{array}$ & 2 & 27 & 0,1 \\
\hline $70 \%$ with twins & 1,6 & 31 & 4,3 \\
\hline
\end{tabular}

Table 3 Values of pole density (pole figure $\{110\}$ ) of the weak initial component, closed to (110)[001] in deformation texture

\begin{tabular}{|c|c|c|c|c|c|}
\hline \multirow[t]{2}{*}{ Rolling treatment } & \multicolumn{5}{|c|}{$\begin{array}{c}\text { Rotation angle (deg) around [001] coinsided with } R D \\
\text { Indices of plane }\end{array}$} \\
\hline & $\begin{array}{c}0.0 \\
(110)\end{array}$ & $\begin{array}{c}6.3 \\
(540)\end{array}$ & $\begin{array}{l}11.3^{2} \\
(320)\end{array}$ & $\begin{array}{l}18.4 \\
(210)\end{array}$ & $\begin{array}{l}26.6 \\
(310)\end{array}$ \\
\hline $\begin{array}{l}\text { 1-2 passes rolling: } \\
50 \% \text { without twins }\end{array}$ & 1.1 & 2.0 & 0.6 & 0.1 & - \\
\hline $50 \%$ with twins & 1.2 & 2.2 & 0.7 & 0.3 & - \\
\hline $70 \%$ without twins & 0.3 & 0.9 & 0.9 & 0.6 & 0.2 \\
\hline $70 \%$ with twins & 0.5 & 0.9 & 0.9 & 0.8 & 0.3 \\
\hline $80 \%$ without twins & 0.1 & 0.2 & 0.6 & 0.5 & 0.3 \\
\hline $80 \%$ with twins & 0.1 & 0.2 & 0.6 & 0.6 & 0.5 \\
\hline $\begin{array}{l}\text { 30-50 passes rolling: } \\
50 \% \text { without twins }\end{array}$ & 1.6 & 2.4 & 0.7 & 0.2 & - \\
\hline $50 \%$ with twins & 1.5 & 2.4 & 0.7 & 0.4 & 0.1 \\
\hline $70 \%$ without twins & 0.5 & 1.0 & 1.0 & 0.8 & 0.2 \\
\hline $70 \%$ with twins & 0.4 & 1.0 & 1.1 & 0.9 & 0.3 \\
\hline $80 \%$ without twins & 0.2 & 0.2 & 0.6 & 0.7 & 0.4 \\
\hline $80 \%$ with twins & 0.1 & 0.2 & 0.5 & 0.8 & 0.5 \\
\hline
\end{tabular}


give track of the distribution of the weak initial component close to (110)[001] in the deformation texture. After reduction to $50 \%$ a distribution maximum is found at the angle $6^{\circ}$. When the degree of deformation is increased, the maximum is shifted towards (310), extending the angle intervals of distribution. Note that in the single crystal subject to the treatment $\mathrm{B}$ the distribution maximum is shifted a little more intensively with an increase in the degree of deformation. The presence of twins also leads to a slight increase in the width of distribution.

Sharp recrystallization textures (Figure 4) are formed after annealing of deformed single crystals. The textures differ for rapid and slow heating. An analysis of the differences is facilitated if one uses the curves of the pole density distribution along TD. An example of such distribution in single crystals with and without twins, which were rolled under the conditions $\mathrm{A}$ to $70 \%$ and annealed at rapid (regime 1) and slow (regime 3) heating, is shown in Figure 5. The characteristics of the pole density distribution for all the recrystallized samples are summarized in Table 4 .

As is seen from Table 4, the maximum of distribution in the samples, which were subject to a $70 \%$ reduction and recrystallization at rapid heating, deviates from the center of the pole figure for $6-10^{\circ}$ and is close to the initial orientation of the single crystal. As the degree of deformation is raised to $80 \%$, deviation of the maximum from the initial orientation of the single crystal increases, as does the width of distribution. The presence of twins has little, if any, effect on the position of the maximum. However, twins cause a slight increase in the width of distribution.

Table 4 Position ( $\alpha_{\mathrm{m}}$, deg) and half width $\left(\beta_{\mathrm{m}}\right.$, deg) of the maximum in central part of pole figure (110) of the main recrystallization texture component.

\begin{tabular}{lcccc}
\hline Rolling treatment & \multicolumn{2}{c}{ Rapid heating } & \multicolumn{2}{c}{ Slow heating } \\
& $\alpha_{m}$ & $\beta_{m}$ & $\alpha_{m}$ & $\beta_{m}$ \\
\hline 1-2 passes rolling: & 6 & 7 & 7 & 9 \\
50\% without twins & 8 & 10 & 14 & 11 \\
50\% with twins & 7 & 12 & 15 & 13 \\
$70 \%$ without twins & 8 & 15 & 14 & 18 \\
$70 \%$ with twins & 10 & 12 & 18 & 19 \\
$80 \%$ without twins & 10 & 16 & 18 & 18 \\
$80 \%$ with twins & & & & \\
30-50 passes rolling: & 6 & 7 & 10 & 10 \\
$50 \%$ without twins & 7 & 10 & 14 & 12 \\
$50 \%$ with twins & 10 & 13 & 16 & 12 \\
$70 \%$ without twins & 8 & 14 & 15 & 20 \\
$70 \%$ with twins & 13 & 17 & 20 & 18 \\
$80 \%$ without twins & 12 & 16 & 21 & 19 \\
$80 \%$ with twins & & & & \\
30-50 passes rolling, high friction: & 10 & 12 & 16 & 16 \\
$70 \%$ without twins & & &
\end{tabular}


(a)

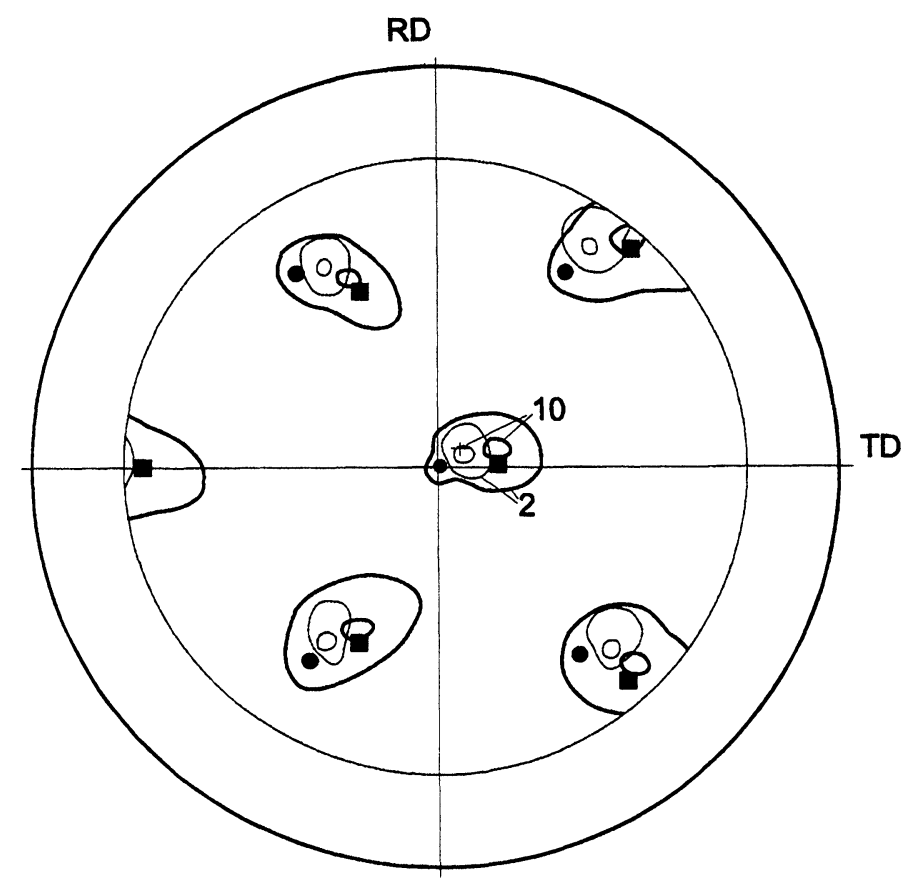

(b)

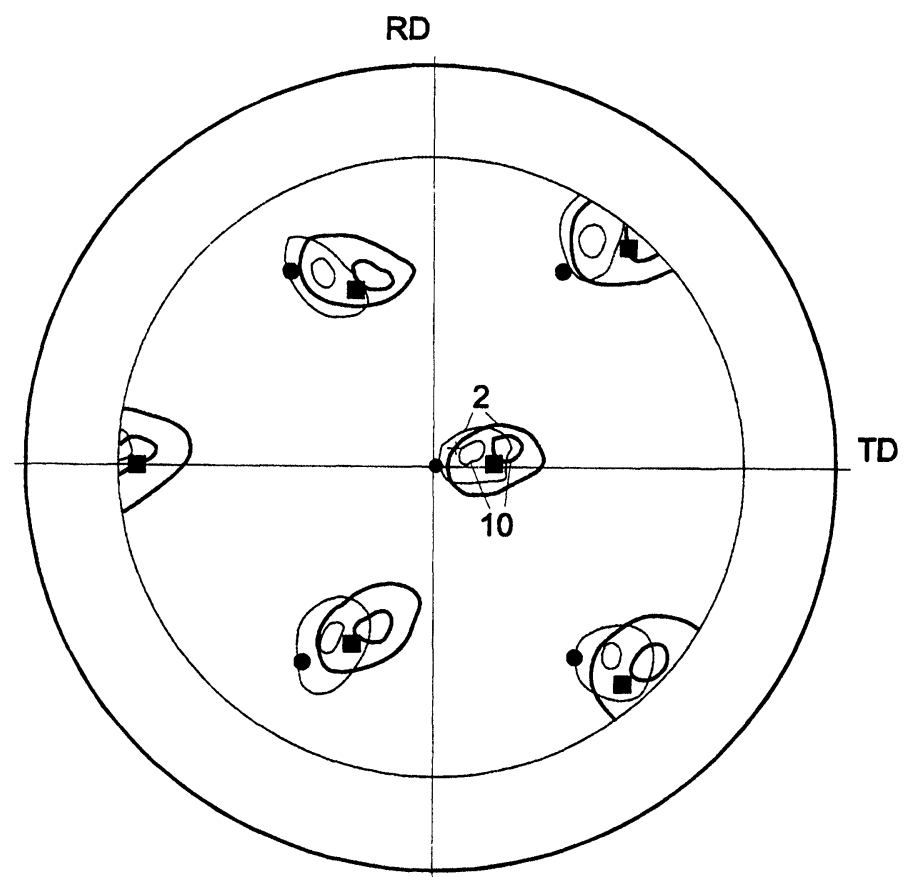

Figure $4\{110\}$ pole figures of (110)[001] crystals, rolled by different regimes to $70 \%$ reduction and recrystallized by slow heating (solid lines) and rapid heating (dotted lines): $\mathrm{a}-\mathrm{A}$ treatment; $\mathrm{b}$ - B treatment. - (110)[001], - (210)[001] 


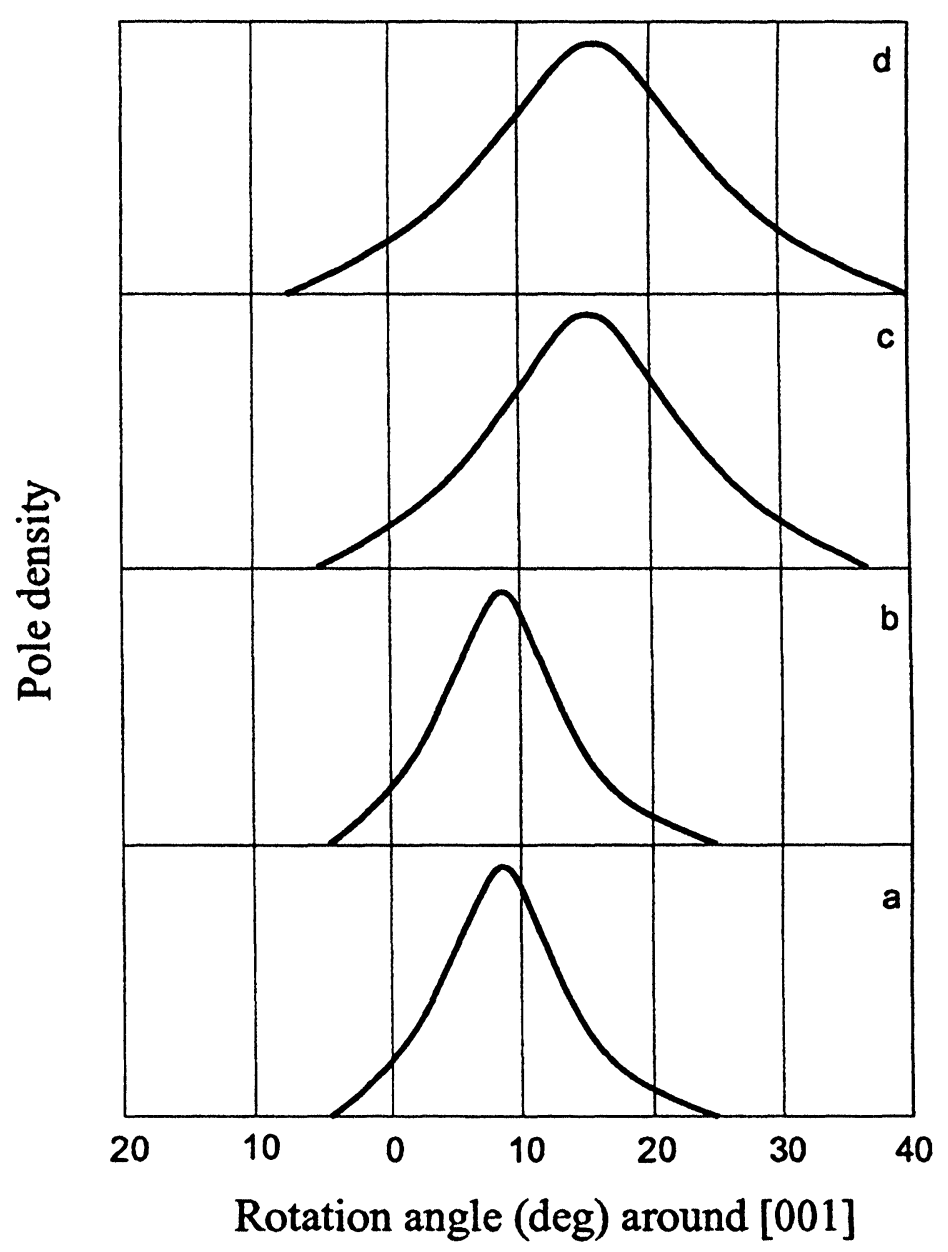

Figure 5 Profiles of recrystallization texture pole density near ND towards TD on pole figures $\{110\}$ in crystal with twins $(b, d)$ and without twins $(a, c)$, rolled to $70 \%$ according A regime: a, $\mathrm{b}$ - rapid heating; c, d - slow heating.

After slow heating the distribution maxima are shifted to larger $\left(10-21^{\circ}\right)$ angles, while the distributions themselves are asymmetrical relative to the modal axis and have a much greater width. It is interesting to note that in single crystals with the total deformation of $50 \%$ the presence of twins causes a sharp shift of the distribution maxima towards (210), while in the absence of twins the shift is much less. With an increase in the total deformation, the differences vanish. The degree of deformation has the same effect on the distribution characteristics as in the case of rapid heating.

Structural examinations show that under slow heating first recrystallization grains appear both in transition bands and kink bands. In twinned single crystals recrystallized grains are formed in deformation twins as well (Figure 6). Subject to rapid heating, recrystallized grains also appear at all structural inhomogeneities. 

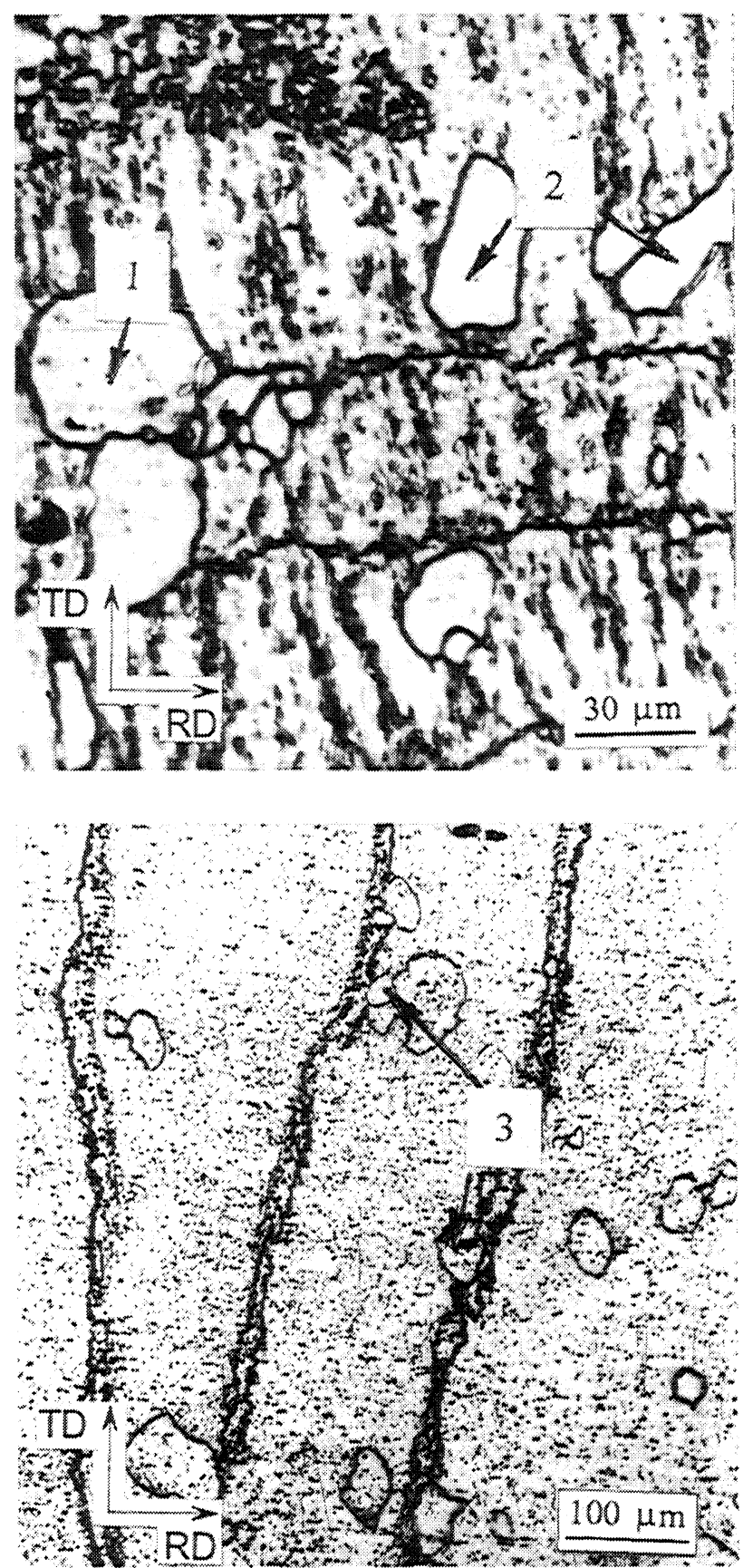

Figure 6 Formation of recrystallization centers in (110)[001] crystal, rolled to $70 \%$ reduction by $\mathrm{A}$ treatment and heated slowly up to $600^{\circ} \mathrm{C}: 1$ - on transition bands, 2 - on kink bands (a); 3 - on twins (b). 
In the case of rapid-heating recrystallization the growing grains have certain orientation relationships with the basic texture components of the deformed matrix. The relationships can be expressed by rotations through angles $\sim 35^{\circ}$ about the axes close to $<110>$. As is known (Dunn, 1954), this rotation corresponds to the conditions of a maximum mobility of grain boundaries. Note that a specific feature of the single crystal under study, deviation of the initial orientation from (110), leads to a noncorrespondence of the produced deformation texture to strictly ideal stable components $\{111\}<112>$. As the degree of deformation is raised, deviation of the basic components from stable positions is enhanced. Correspondingly, the orientation of preferably growing recrystallized grains is changed.

Growing recrystallized grains, which are formed during slow heating, are not connected with the matrix texture by the orientation relationships characteristic of a maximum mobility of the grain boundaries. For example, the orientation relationship between $\{111\}<112>$ and $\{210\}<001>$ can be expressed by rotation about the axis $<745>$ through the angle $39.7^{\circ}$. Determination of the character of the orientation relationship between the preferred orientations, which are obtained during slow heating, and the deformed matrix texture yields a great variety of rotation angles and axes $\left(30-48^{\circ}\right.$ about the axes located closer to $\left.<111>\right)$.

\section{DISCUSSION}

It is shown experimentally that all structural inhomogeneities in deformed single crystals participate in formation of recrystallization centers both under rapid and slow heating. A broad variation of quantitative relationships between texture inhomogeneities of various types has little effect on the recrystallization texture. Then explaining the differences in recrystallization textures formed at different heating rates by preferred nucleation of the centers at certain inhomogeneities, as is done in (Livshitz 1969, 1970, 1972; Gubernatorov, 1975), is not quite correct.

The surprising thing is that the recrystallized grains growing under slow heating have orientations, which are not connected with the matrix texture by the orientation conditions of a high mobility of the boundaries in spite of centers with high-mobility boundaries may arise at structural inhomogeneities of the matrix (see Table 3). Two alternatives can be considered to account for this paradox. Either the orientation relationships typical of high-mobility boundaries are altered during slow heating or the appearance of the recrystallization centers capable of growing at large rates is hampered under slow heating. The first supposition is hardly probable. In these experiments lowering of the heating rate should not change recrystallization temperatures to such an extent as to modify completely the orientation conditions of maximum-mobility boundaries. The other supposition seems to be justified. Let us consider it in more detail.

As is known, the driving force of primary recrystallization is the gradient of volume and boundary energies. However, in the case of slow heating the amount of stored volume energy considerably lowers as a result of recovery processes. In this case the critical dimension of the centres (i.e. the dimension, starting from which their growth becomes energetically favourable) is determined by the ratio between the energy increment due to enlargement in the surface of the boundaries of the growing center and the energy of the matrix subgrain boundaries absorbed by the center. 
The centers forming minimum-energy boundaries (subboundaries) with the surrounding subgrains will have the smallest critical dimension. These centres will be represented in the first place by subgrains possessing orientations of the basic components of the deformation texture. The critical dimension of the centers will be slightly larger than the mean dimension of the subgrains. Although the growth rate of such centers is small owing to a low mobility of low-angle boundaries, an increase in the subgrain dimensions can cause a considerable drop in the driving force.

Centers possessing a high specific boundary energy have a large critical dimension, lowering the probability of their formation. If the matrix texture includes preferred components of the $\{111\}<112>$ type, nuclei with the orientation (110)[001], whose boundary energy is at a maximum in the given matrix (Dunn and Walter, 1965), will have the largest critical dimension.

As the temperature is elevated, the energy of large-angle boundaries lowers to a greater extent than that of low-angle boundaries. The result will be a decrease in the critical dimension of the nuclei forming high-mobility boundaries with the matrix and an increase in the fraction of the corresponding component in the matrix.

So, under conditions of slow heating the orientation dependence of the critical dimension of nuclei limits the number of recrystallization centers whose orientation satisfies the conditions of formation of maximum-mobility boundaries. This lowers their contribution to the recrystallization texture. Under these conditions grains with compromising orientations (i.e. those having a sufficiently high mobility of the boundaries and not too large critical dimension of the nuclei) will develop during recrystallization. Most probably, this factor explains the specific features of the recrystallization texture formed under slow heating: a high (as compared to the one observed during rapid heating) scattering of the texture and a shift of its maximum.

The influence of the orientation relationship of recrystallization nuclei to the matrix on the critical dimension of the nuclei for the case of secondary recrystallization in the Fe-3\% Si alloy was analyzed by Gubernatorov, Sokolov, Sbitnev (1995).

Considering what has been said above, the notion of oriented nucleation needs to be defined more exactly. It should be understood not only as limitation of orientations of potentially possible centers by structural conditions of their formation but also as restriction of orientations of the recrystallization centers being formed, due to the orientation dependence of the critical dimension of nuclei.

\section{CONCLUSIONS}

The following conclusions, can be drawn from the study:

1. It is shown that particular rolling conditions of a single crystal with the orientation close to (110)[001] can incur changes in the intensity ratio of the basic doublet components of the $\{111\}<112>$ type. In this case the quantitative relationships between the structural inhomogeneities (transition bands and kink bands) in the deformed state vary over broad intervals. Many passes rolling with a high friction coefficient can completely eliminate formation of transition bands in the structure of the deformed single crystal.

2. When single crystals, which were deformed under different regimes, are subject to rapid heating, a sharp texture with the preferred orientation close to the initial orientation of single crystals is formed. As the degree of deformation is increased, 
the preferred orientation of the formed recrystallization texture is slightly shifted towards (320).

In all the cases studied the recrystallization texture, which appears under slow heating, differs from the texture formed under rapid heating. The preferred orientation of the former texture exhibits a stronger deviation from the initial orientation towards (210)-(310). The deviation angle increases with the degree of deformation.

3. The presence of twins in deformed single crystals has little effect on the recrystallization textures in single crystals subject to a $70 \%$ and $80 \%$ reduction. In single crystals reduced to $50 \%$ and subject to slow heating twins ensure appearance of the orientaion close to (320), whereas in the absence of twins the recrystallization texture approximates the initial one.

4. It is shown that first recrystallization centers are formed at structural inhomogeneities of different types (transition bands, kink bands and deformation twins). So, a change in the recrystallization texture under different heating conditions cannot be attributed to a selectivity of the recrystallization center formation at certain types of structural inhomogeneities.

5. The formation of the recrystallization texture (310)-(210)[001] under slow heating of deformed single crystals (110)[001] is due to an oriented nucleation. Here the oriented nucleation is taken to mean not only limitation of the orientation at structural inhomogeneities but also restriction of the orientation of really existing recrystallization centers, the restriction being due to the influence of the orientation relationships between the nuclei and the matrix on the critical dimension of the nuclei.

Our study supports the opinion voiced by $\mathrm{H}$. $\mathrm{Hu}$ who attributed formation of the recrystallization texture (210)-(310)[001], which takes place under slow heating or long low-temperature soaking of a deformed single crystal (110)[001], solely to particular annealing conditions. It also confirms his supposition that the presence of the weak component (110)[001] is insufficient for the Goss texture to be formed in the deformation texture.

\section{References}

Ageev, L. M., Vydrin, V. N. and Zykov, G. A. et al. (1973). The Formation of Deformation Texture in $\{110\}<001>$ crystals of Fe-3\% Si during the Rolling-Drawing Process. Fiz. Met. Metalloved. Vol. 35, p. 1015-1025.

Bryshko N. A., Gubernatorov, V. V. and Sokolov, B. K. (1985). The Development of Deformation and Recrystallization Textures in Fe-3\% Si during Treatments Included Angle Rolling. Fiz. Met. Metalloved. Vol. 60, p. 756-763.

Dunn, C. G. (1954). Cold-rolled and Primary Recrystallization Texture in Cold-rolled Single Crystals of Silicon-iron. Acta Met. Vol. 2, p. 173-183.

Dunn, C. G. and Walter, J. L. (1965). Secondary Recrystallization. In: Recrystallization, Grain Growth and Textures. Ch. 10. Ohio, Metals Park, p. 461-521.

Furubayashi, E. (1969). An Origin of the Recrystallized Grains with Preffered Orientations in Cold Rolled Fe-3\% Si. Trans. Iron Steel Inst. Japan. Vol. 9, p. 222-238.

Furubayashi, E. and Kikuchi, T. (1977). A study of surface textures in cold-rolled single crystals of silicon iron with reference to new lubricating materials. Tetsu to Hagane. Vol. 63, p. 460-465.

Gorelik, S. S. and Goldstein, V. Ya. (1968). The Recrystallization of the Cold Rolled Transformer Steel. Fiz. Met. Metallowed. Vol. 26, p. 129-138.

Gubernatorov, V. V. (1975). The Investigation of the Process of Texture Formation during Primary and Secondary Recrystallization in Fe-3\% Si. Ph.D. Thesis. Institut of Metal Physics Russian Academy of Sciences.

Gubernatorov, V. V., Sokolov, B. K. and Sbitnev, A. K. (1995). On Texture Formation in Metals during Recrystallization. I. The Effect of a Texture on Relative Rate of Grains Growth. Fiz. Met. Metalloved. In print. 
Honeycombe, R. W. K. (1968). The Plastic Deformation of Metals. Edward Arnold (Publishers) Ltd. $\mathrm{Hu}, \mathrm{H}$. (1960). The Formation of (110)[001] Recrystallization Texture in a Cold-rolled and annealed (110)[001] Crystal of Silicon-iron. Acta Met. Vol. 8, p. 124-126.

$\mathrm{Hu}$, H. (1961). A Study of the Texture Formation in Rolled and Annealed Crystals of Silicon-iron. Trans. Met. Soc. AIME. Vol. 221, p. 130-140.

$\mathrm{Hu}, \mathrm{H}$. (1966). Annealing of Crystals of Silicon-iron. In: Recovery and Recrystallization of Metals. Ed. L. Himmel. In Russian, p. 273-326.

Livshitz, B. G., Novikov, V. Yu. and Roshina, L. V. (1969). Structure Investigation of (110) Crystal of Silicon Iron at the beginning of Primary Recrystallization. Fiz. Met. Metalloved. Vol. 27, p. 865-869.

Livshitz, B. G., Novikov, V. Yu., Roshina and L. V. (1970). The Effect of a Low-temperature Annealing on Primary Recrystallization Texture of Silicon Iron Crystals. Izv. Akad. Nauk SSSR, Ser. Fiz. Vol. 34, p. 249-254.

Livshitz, B. G., Novikov, V. Yu. and Roshina, L. V. (1972). The Investigation of Texture Formation during Primary Recrystallization in Deformed Crystal of Silicon Iron with $\{110\}<001>$ Initial Orientation. I. The Modification of Structure during the Annealing. Fiz. Met. Metalloved. Vol. 34, p. 801-810.

Taoka, T., Furubayashi, E. and Takeuchi, S. (1967). Formation of Cold-Rolled Texture and Recrystallization Texture in Single Crystals of 3\% Silicon Iron. Part 1. Cold-rolled Texture. Trans. Nation. Res. Inst. Metals. Vol. 9, p. 155-185.

Taoka, T., Furubayashi, E. and Takeuchi, S. (1967). Formation of Cold-rolled Texture and Recrystallization Texture in Single Crystals of 3\% Silicon Iron. Part II. Recrystalized Texture. Trans. Nation. Res. Inst. Metals. Vol. 9, p. 187-207. 